\title{
sciendo DESIGN OF GRINDING MACHINE SPINDLE
}

doi:10.2478/mape-2018-0010

Date of submission of the article to the Editor: 04/2018

Date of acceptance of the article by the Editor: 07/2018

MAPE 2018, volume 1, issue 1, pp. 69-76

Ing. Lukas Rudolf

Assoc. Prof. Ing. Jiri Fries, PhD.

Ing. Oldrich Ucen, PhD.

Ing. Tomas Kubin, PhD.

Ing. Lukas Kudrna

VSB - Technical University of Ostrava, Czech Republic

\begin{abstract}
When grinding high demands are usually placed on the geometrical tolerances of the workpiece surface. For this reason, the spindles of the grinding machines are normally designed with requirements for a minimum position change of the grinding disks due to external forces and bending moments. The design theory of these spindles is relatively well elaborated, as it represents the most frequently used solution in practice. However, there are also cases where it is necessary to grind some hard-to-reach areas, using a great ejection of the spindle. In these cases, it is necessary to reassess the required geometrical tolerances with regard to its necessity to comply with the minimal changes in the position of the grinding discs due to the great ejection. Where it is necessary to maintain high geometrical tolerances, it is necessary to ensure a greater rigidity of the spindle. This rigidity is usually improved by increasing its diameter. By doing this we also increase the weight of the spindle that is heavily ejected, and thus its deformation can occur due to gravity forces. That is why it is necessary to analyse the deflection of the spindle depending on its ejection in the course of its design. In the case we increase the diameter of the grinder spindle the possible applicable grinding disc diameter decreases, due to the growing size of its housing. Any grinding of hard-to-reach surfaces is therefore done in particular to improve the quality of the surface with low requirements on the geometrical tolerances. This article deals with the design patterns for a spindle used in axial grinding for inner rotating surfaces. The article contains a spindle design solution and an analysis of its deflections, depending on its ejection, and the size of the passive forces.
\end{abstract}

Keywords: grinding machine, spindle, design

\section{INTRODUCTION}

A spindle of grinding machine may be structurally designed in two variants. A first variant with a spindle able to pass through the all pipe, supported on both sides, is an adverse one, due to the necessity of suctioning chips from grinding on one side of the workpiece, and also because of the appreciable demands on the length of the spindle and its design complexity. A second structurally simpler variant of the grinder arrangement is the one where the spindle is supported on one side, and the grinding wheel is placed on the operable structure. This spindle is placed on a moving truck and supported in all its length with supports of the spindle. The grinding machine layout is shown in Fig. 1. 


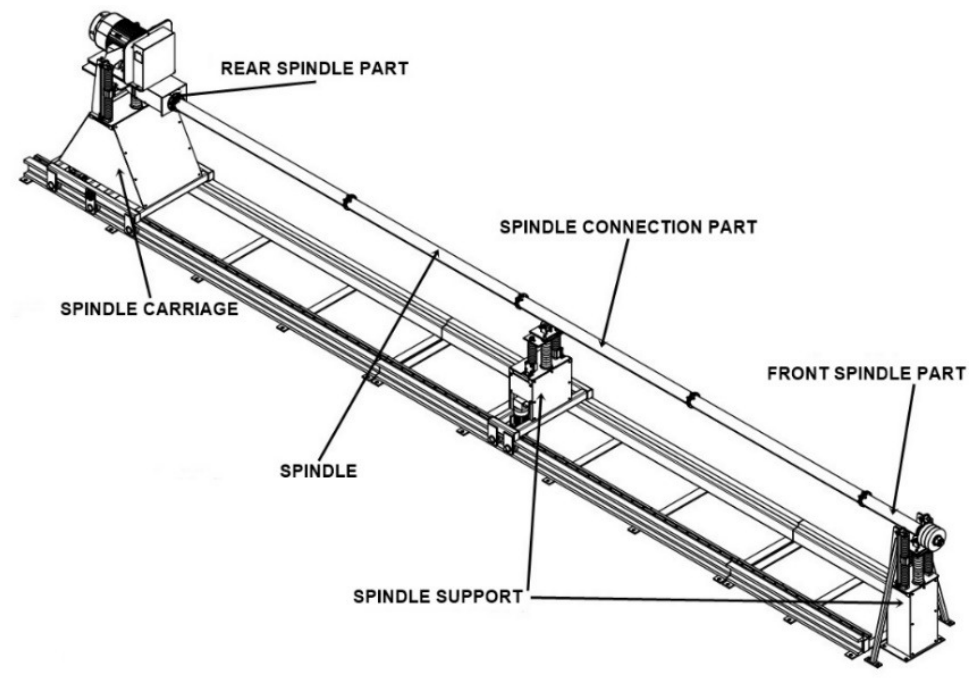

Fig. 1. The internal pipe diameter grinder

\section{SPINDLE'S DESIGN REQUIREMENTS TAKEN INTO ACCOUNT}

\subsection{The spindle parts deflection}

We try to minimize the number of parts in the spindle with regard to the operational reliability, and for this reason the distance between the two bearings is selected considering the allowed shaft deflection between bearings, which is given by the following relation (Shigley et al., 2010; Kotus et al., 2013).

$$
y=\left(1 \cdot 10^{-4} \div 5 \cdot 10^{-4}\right) \cdot L[\mathrm{~mm}]
$$

where:

$y$ is the deflection of the shaft between the two bearings [mm],

$L$ the distance between the two bearings [mm].

It is necessary to use an appropriate dimension of the shaft spindle to create the minimum necessary load on the bearing using its own weight. For the used bearings it is expressed by the relationship (SKF Group, 2007).

$$
P_{m}=0.01 \cdot C_{0}[\mathrm{~N}]
$$

where:

$P_{m}$ is the minimum equivalent load $[\mathrm{N}]$,

$C_{0}$ is the static load capacity of the bearing $[\mathrm{N}]$.

In case of the failure to establish proportionally minimum bearing preload slips between the balls and their races can occur, caused by the inertia force of the balls, the cage and friction in the lubricant. This slippage causes significant wear, shortens the life of the bearing and warmings. In the table 1 is a comparison of three variants for connection part of the spindle. The proposed dimensions of the intermediate shaft used in the analysis of these variants are based on the used bearing. The values in the table 1 are valid for a diameter under the $31 \mathrm{~mm}$ bearing and the $42 \mathrm{~mm}$ shaft shoulder.

Table 1

\begin{tabular}{|c|c|c|c|}
\hline The number of the spindle connection parts [1] & 2 & 3 & 4 \\
\hline Distance between bearings [mm] & 3,850 & 2,566 & 1,925 \\
\hline Number of bearings [1] & 4 & 6 & 8 \\
\hline Reaction force in the bearing [N] & 231.1 & 148.7 & 109.4 \\
\hline Required reaction force in the bearing [N] & 112 & 112 & 112 \\
\hline Maximum deflection between the bearings $y[\mathrm{~mm}]$ & 6.326 & 0.756 & 0.358 \\
\hline Allowed deflection between the bearings [mm] & 1.150 & 0.766 & 0.575 \\
\hline Suitable [1] & NO & YES & $\mathrm{NO}$ \\
\hline
\end{tabular}

Options analysis 
With regard to the simplicity in the analysis of these options the size of connecting elements were not considered. The characteristics of the used connecting shaft with the length of 2,489 $\mathrm{mm}$, including the final proportions of this shaft, are summarised in the table 2.

Table 2

Used variant

\begin{tabular}{|l|r|}
\hline Distance between bearings [mm] & 2.489 \\
\hline Number of bearings [1] & 4 \\
\hline Reaction force in the bearing [N] & 143.1 \\
\hline Required reaction force in the bearing [N] & 112 \\
\hline Maximum deflection between the bearings $\boldsymbol{y}[\mathrm{mm}]$ & 0.732 \\
\hline Allowed deflection between the bearings [mm] & 0.743 \\
\hline
\end{tabular}

\subsection{Sufficient passive forces for grinding}

In the course of grinding a total cutting force appears between the grinding wheel and workpiece, acting in a general direction. Total cutting force is distributed into the three mutually perpendicular components, as shown in Fig. 2. The passive force $F_{P}$ is the most important element acting here, which is perpendicular to the grind surface. In the feed direction there acts feed force $F_{F}$ and in the direction of the cutting speeds there acts cutting force $F_{C}$. For the optimal design of the spindle it is necessary to determine the optimal size of the $F_{P}$. This size varies according to (Kocman, 2011) in the range of (3) and also according to (4) (UNZM, 2017).

$$
\begin{aligned}
& F_{P}=(1.2 \div 3) \cdot F_{C}[\mathrm{~N}] \\
& F_{P}=(2 \div 10) \cdot F_{C}[\mathrm{~N}]
\end{aligned}
$$

The optimal theoretical passive force is relatively difficult to determine. It is therefore necessary to take into consideration the various values of the force during the designing, with regard to its difficulty determination of the passive force. The passive force itself is in the selected design layout created by the weight of spindle itself depending on its ejection. Feed force is made up of feed drive of the spindle truck and the cutting force is generated by the drive of the.

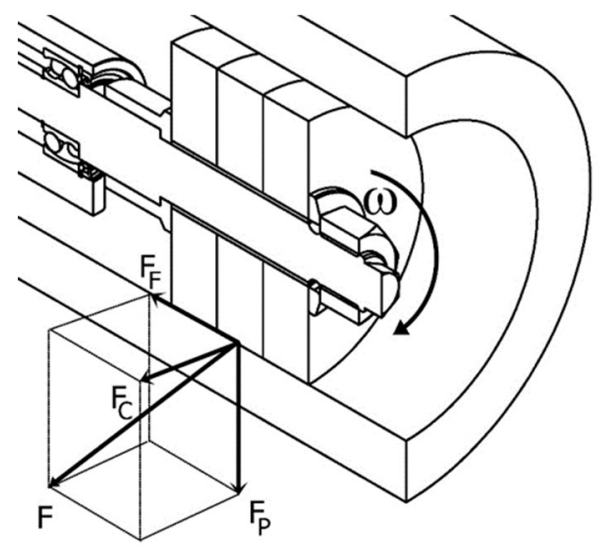

Fig. 2. The forces distribution

\subsection{The minimal length of the spindle}

With regard to the requirements on the spindle and with regard to the minimum need of the built-up area, there is an effort to minimize the worked length of the pipe. This can be achieved by machining pipes from both sides, with to the rotation of the workpiece around its vertical axis.

\subsection{Easy replacement of the grinding wheels}

During grinding the chips are not easily removed from the place of processing. There is excessive fouling occurring on the grinding wheels. Using more wheels arranged successively 
reduced their frequent replacement and the need for necessary dressing. The end part of the spindle is equipped with a hexagon bar for its easy stoppage when replacing wheels. The grinding wheels are placed on the spindle via a quenched bushing, which increases its lifetime. Wheels are further secured by flanges, whose dimensions are based on standards (UPN, 1977). In the solved case it is possible to use a wheels in the range $150-250 \mathrm{~mm}$. Design of the front part as shown in Fig. 3.

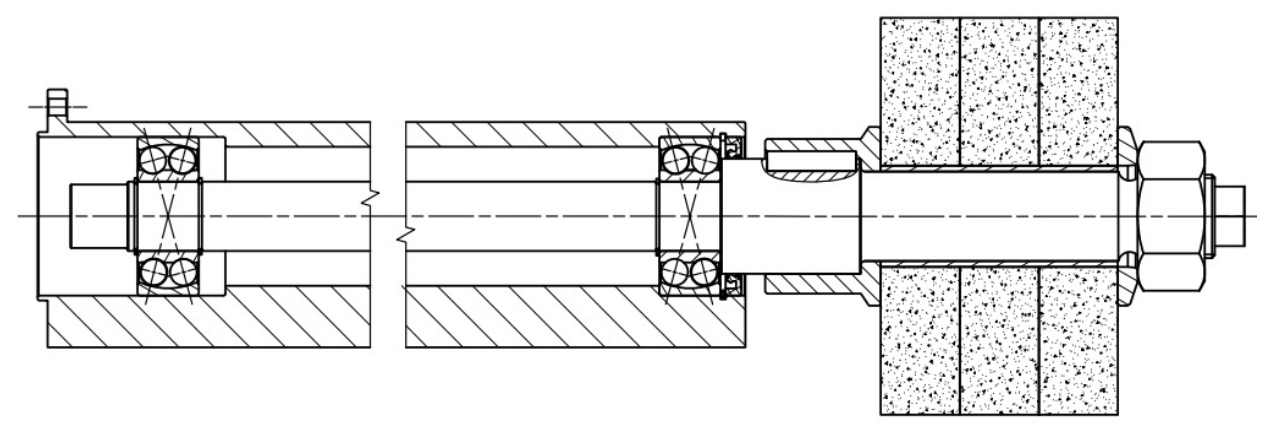

Fig. 3. The front part of the spindle

\subsection{Reliable and easy connection of individual parts of spindle}

As there are vibrations occurring in the course of grinding, there is an effort to minimise the transmission of vibrations from the grinding wheels to the other parts of the grinder. This vibration transmission is minimised by using the elastomeric coupling. These couplings are characterized by a good reduce of vibration transmission and allow for the elimination of the thermal expansion thanks to their axial movement. Elastomeric coupling also compensate for the parallel and angular misalignment of the different parts of the spindle. The elastomeric couplings are also a relatively cheap.

\subsection{Torque transfer to the spindle}

Use a belt drive is most appropriate for torque transfer from the electric motor to the spindle. Belt drive in case of overload works as a safety clutch and in case of the emergency and spindle blockade there will be no damage to the engine. A belt drive is also less sensitive to vibrations. Small variations in the transmission number are thanks to the slip negligible for this application. The rear spindle part, which enables this transfer, is shown in Fig. 4.

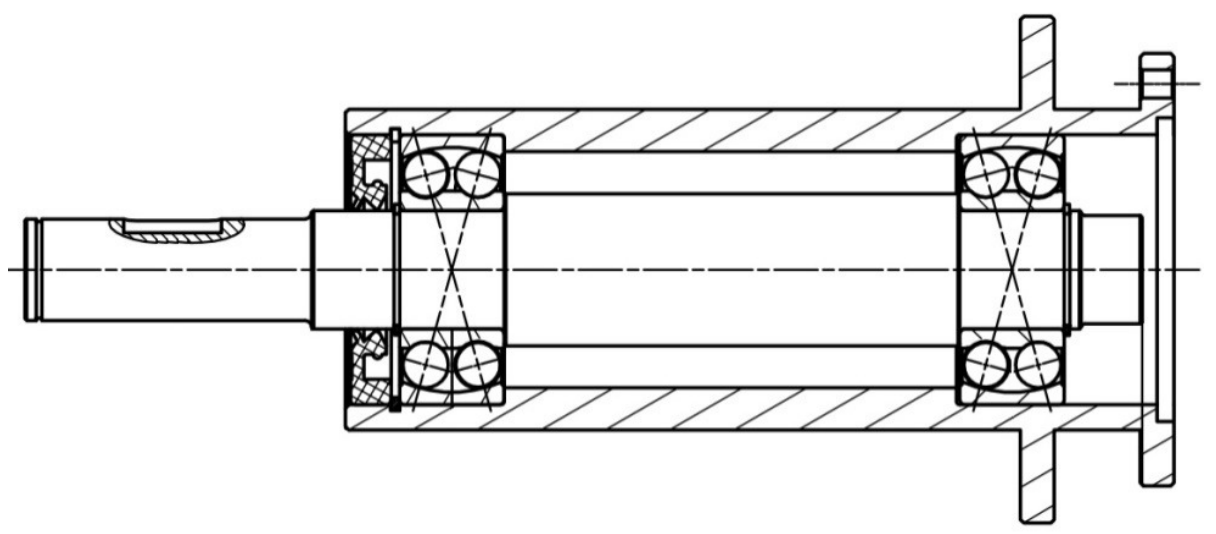

Fig. 4. The rear part of the spindle

\subsection{The spindle modularity}

It is appropriate to use a modular structure due to the possibility of the unification in production. This arrangement allows a considerable range of workpiece lengths and has a significant 
influence on the design simplicity of modifications. For the whole construction of the spindle was used a one model of a self-aligning ball bearing. The connection part of the spindle is illustrated in Fig. 5.

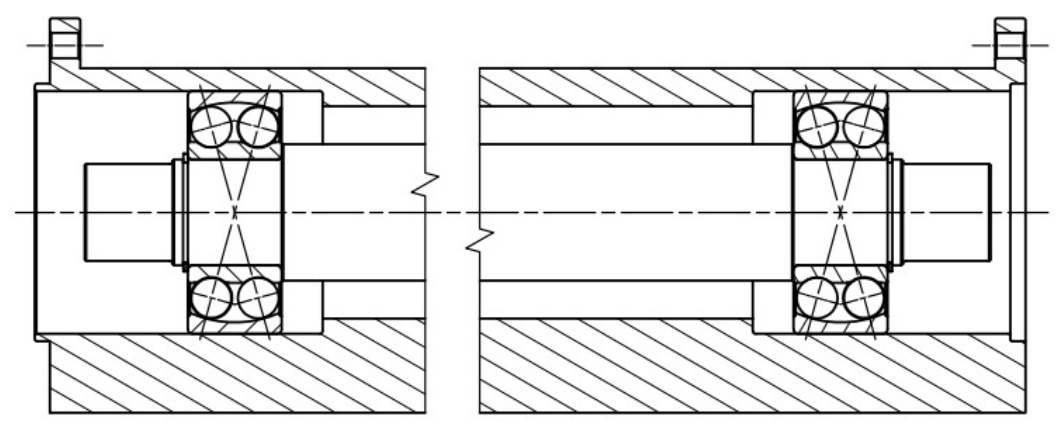

Fig. 5. The spindle connecting part

\subsection{Tipping over of the pipe grinder}

It is required for the design to eliminate the possibility of tipping the grinder over with regard to the length of the spindle. This tipping could cause an impact effect and the emergence of dynamic forces. These dynamic forces would result in a reduction in the lifetime of the whole structure of the grinder. During processing operations the spindle is exposed to the passive force, which 'lifts" it, but has a very low rigidity. Accordingly, in this solution the centre of gravity in the grinder is placed in front of the rotation axis of the support guides.

\subsection{The spindle deflection during grinding}

Due to a significant ejection of the spindle it is necessary to take into account the size of the passive force and analyse the deflections of the spindle. For selected design the analysis of the end part deflection of an idealized spindle has been done for chosen passive forces from range (3) and (4) using the FEM methods. In the FEM analysis however the effect of the cutting force was not considered. Cutting force causes the deflection of the spindle in a horizontal direction from the centre line of the workpiece (Kováč et al., 2014). Bend from cutting force reduces the spindle deflection depending on the inner radius of the workpiece. The spindle deflection depending on the passive force size, are shown in Figs. 6 and 7.

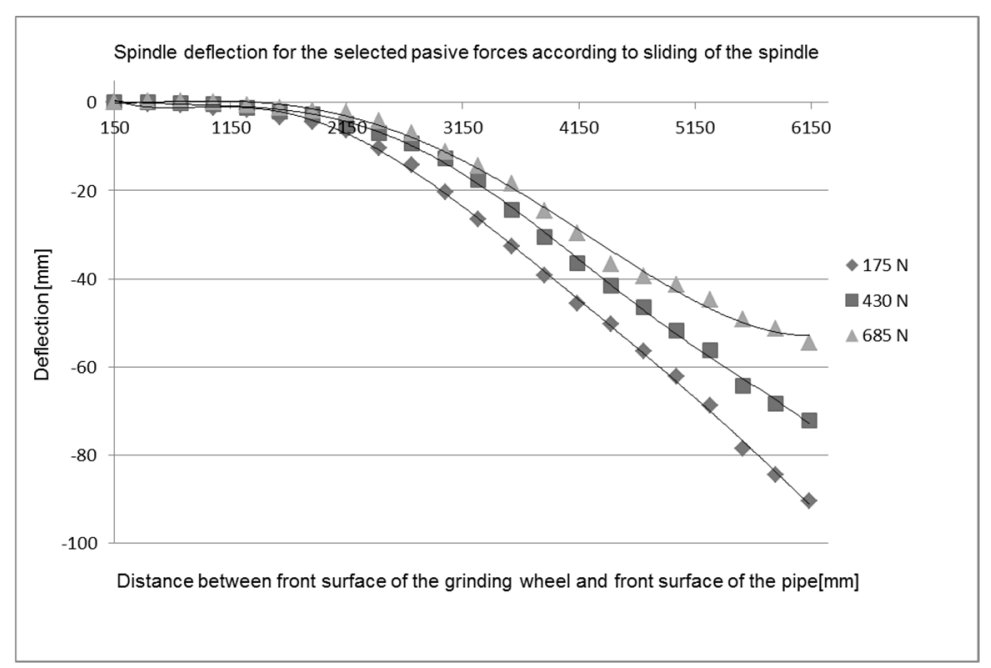

Fig. 6. Course of deflection depending on the ejection for the size of a passive force of $175 \mathrm{~N}$ and $430 \mathrm{~N}$ and $685 \mathrm{~N}$ 


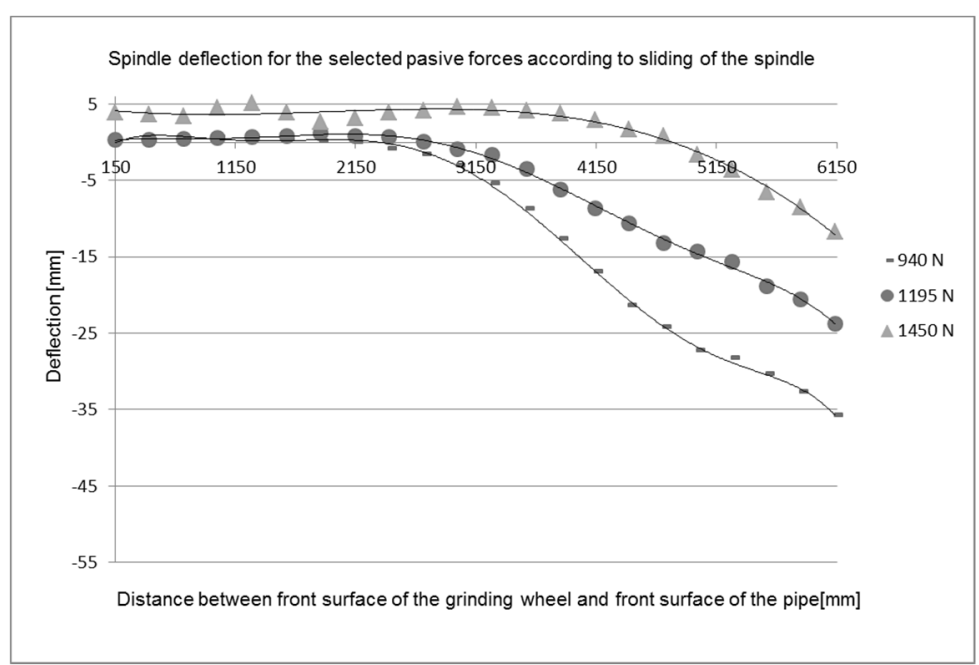

Fig. 7. Course of deflection depending on the ejection for the size of a passive force of $940 \mathrm{~N}$ and 1,195 $\mathrm{N}$ and $1,450 \mathrm{~N}$

\section{POSSIBILITY TO CONTROL THE PASSIVE FORCES}

With regard to the possible versatility of the grinder, used for the desired range of the worked diameters of pipes, and also thanks to the range of the passive forces, it is necessary to allow for the spindle height positioning. Lift of the spindle in the designed case is implemented using three actuators. With regard to the progress of the deflection and to the elimination of the collision risks between the worked pipe and the spindle the optimum sizes of the passive forces were established for the used cutting force $F c$, depending on the outer diameter of the grinding wheel and inner diameter of the pipe and according also to other conditions (Rudolf et al., 2016; Rudolf et al., 2017; Beňo et al., 2016).

\section{DISSCUSION}

In processing the analyses of deflection, the cutting forces were not taken into account, and so the change of deformation in the direction of the weight depending on the radius of the processed pipe was not taken into consideration. Furthermore, the speed of rotation acting on the workpiece was not taken into consideration as well. These measures would complicate the analyses significantly, but they would cause less bending of the spindle in the direction of the acting weight. The proposed theoretical courses of the strokes must be corrected in the course of the operation, depending on the diameter of the workpiece pipe and on the wear of the grinding discs. One uncorrected course of the spindle lift is illustrated in Fig. 8.

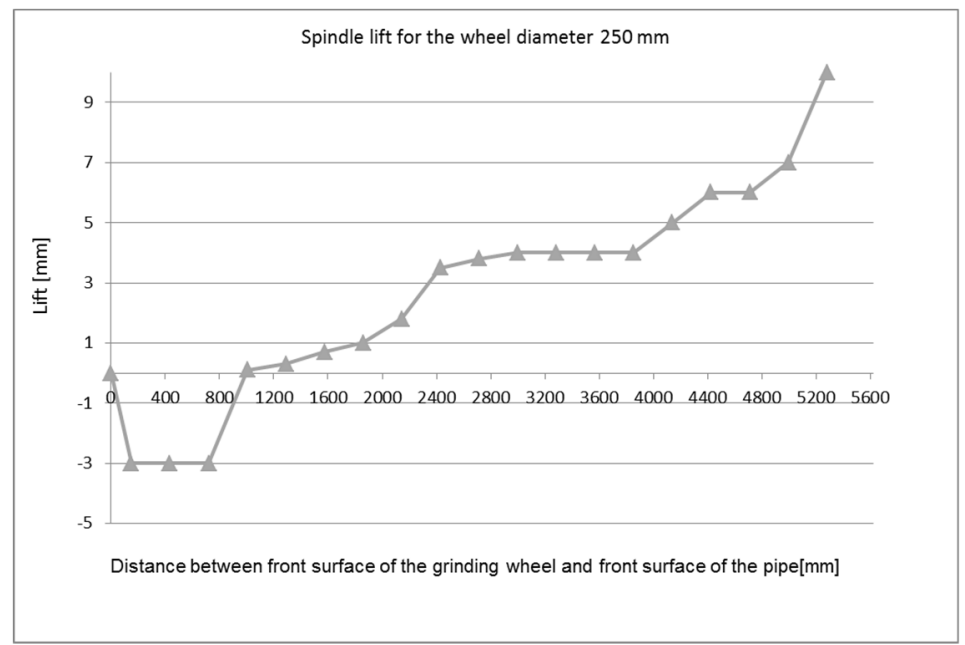

Fig. 8. The theoretical course of the spindle lift for the wheel diameter $250 \mathrm{~mm}$ 


\section{CONCLUSION}

It is necessary to take into account the significant range of passive forces acting on the grinding wheels in the design of the grinder with long spindle, and also to optimize the dimensions of the individual spindle parts with regard to the allowed deflection and external load force. The parts of spindle should be designed with regard to its possible modularity. The front part of the spindle shall be structurally designed to simplify the fast and easy grinding wheels replacement. In Table 3 is shown the theoretical lift design for the practical task. According on this table we select the suitable size of the passive forces in accordance with the input parameters such as the inner diameter of the pipe, rejection of the spindle, and the wheel diameter. Depending to the selected passive force we deduct from the graph the required spindle lift according on its ejection. This lift is entered into the system for actuator lift control. The load on the spindle drive will be detected in testing operation. Depending on the load we can then determine the lift correction for lift.

Table 3

Recommended values of passive forces depending on ejection of the spindle and the diameter of the grinding wheels

\begin{tabular}{|c|c|c|c|c|}
\hline $\begin{array}{l}\text { The distance } \\
\text { between face of } \\
\text { the grinding wheel } \\
\text { and the face of the } \\
\text { grinder [mm] }\end{array}$ & $\begin{array}{c}\text { Wheel diameter } \\
150[\mathrm{~mm}]\end{array}$ & $\begin{array}{c}\text { Wheel diameter } \\
200[\mathrm{~mm}] \text { and } 250 \\
{[\mathrm{~mm}]}\end{array}$ & $\begin{array}{l}\text { Wheel diameter } \\
150 \text { [mm] or the } \\
\text { inner diameter of } \\
\text { the pipe up } \\
190 \text { [mm] }\end{array}$ & $\begin{array}{l}\text { Wheel diameter } \\
200[\mathrm{~mm}] \text { or } 250 \\
\text { [mm] or the inner } \\
\text { diameter of the } \\
\text { pipe over } \\
190[\mathrm{~mm}]\end{array}$ \\
\hline 150 to 3,150 & $\begin{array}{c}175 \mathrm{~N} \\
\text { to } \\
1,195 \mathrm{~N}\end{array}$ & $\begin{array}{c}175 \mathrm{~N} \\
\text { to } \\
1,195 \mathrm{~N}\end{array}$ & $\begin{array}{l}\text { Proceed from the } \\
\text { second set of } \\
\text { criteria }\end{array}$ & $\begin{array}{l}\text { Proceed from the } \\
\text { second set of } \\
\text { criteria }\end{array}$ \\
\hline 3,150 to 3,570 & $\begin{array}{l}\text { Proceed from the } \\
\text { second set of } \\
\text { criteria }\end{array}$ & $\begin{array}{l}\text { Proceed from the } \\
\text { second set of } \\
\text { criteria }\end{array}$ & $\begin{array}{c}685 \mathrm{~N} \\
\text { to } \\
1,195 \mathrm{~N}\end{array}$ & $\begin{array}{c}430 \mathrm{~N} \\
\text { to } \\
1,195 \mathrm{~N}\end{array}$ \\
\hline 3,570 to 6,135 & $\begin{array}{l}\text { Proceed from the } \\
\text { second set of } \\
\text { criteria }\end{array}$ & $\begin{array}{l}\text { Proceed from the } \\
\text { second set of } \\
\text { criteria }\end{array}$ & $\begin{array}{c}1,195 \mathrm{~N} \\
\text { to } \\
1,450 \mathrm{~N}\end{array}$ & $\begin{array}{c}940 \mathrm{~N} \\
\text { to } \\
1,590 \mathrm{~N}\end{array}$ \\
\hline
\end{tabular}

\section{ACKNOWLEDGEMENTS}

This article has been written in connection with the project The research and analysis of modern technologies in manufacturing practice, reg. no. SP2018/3 supported by Specific Research program financed by the Ministry of Education, Youth and Sports.

\section{REFERENCES}

Beňo, P., Marienčík, J., Turis, J., Kozak, D., Konjatić, P. Friction factor dependence on the load and revolutions in sliding bearings without relubrication. In: Tehnički vjesnik. Vol.23, No.4 (2016), p. 997-1001, WOS:000382353400010. ISSN 1330-3651

Kocman, K. (2011). Technologicke procesy obrabeni [Technological Processes of Grinding]. Brno: Akademicke nakladatelstvi CERM.

Kotus, M., Holota, T., Pauliček, T., Petrík, M., Sklenár, M. Quality and reliability of manufacturing process in automation of die-casting. In Advanced Materials Research. ISSN 1022-6680, 2013, vol. 801, special iss., p. 103-107, eid=2-s2.0-84886256844.

Kováč, I., Mikuš, R., Žarnovský, J., Ružbarský, J. Nitrogen effect on mechanical and tribological properties of STN 415230 steel surface layer. In Advanced Materials Research. ISSN 1022-6680, 2014, vol. 1059, 11-17pp. eid=2-s2.0-84961313646.

Matiskova, D., Kotus, M., Balara, M. Automatic thermal control system with temperature difference or derivation feedback. TEM Journal - Technology education management informatics. Volume: 5, Issue: 1 (2016), 60-66 pp. WOS:000376387700010. ISSN: 2217-8309.

Rudolf, L., Fries, J. Design issue of grinding machines spindle used for the interior diameters of long pipes. In $16^{\text {th }}$ SGEM 2016. Albena, Bulgaria, 2016, 255-262 pp. WOS:000395499700033, ISSN: 1314-2704.

Rudolf, L., Fries, J., Učeň, O. The method of detecting movements of the machine tool foundations. In $17^{\text {th }}$ SGEM 2017. Albena, Bulgaria, 893-900 pp. eid=2-s2.0-85032474005, ISSN: 1314-2704. 